\title{
Adiponectin receptor 2 is negatively associated with lymph node metastasis of colorectal cancer
}

\author{
MASAYA HIYOSHI ${ }^{1}$, NELSON H. TSUNO ${ }^{1,2}$, KENSUKE OTANI $^{1}$, KAZUSHIGE KAWAI ${ }^{1}$, TAKESHI NISHIKAWA ${ }^{1}$, \\ YASUTAKA SHUNO ${ }^{1}$, KAZUHITO SASAKI ${ }^{1}$, KUMIKO HONGO ${ }^{1}$, MANABU KANEKO ${ }^{1}$, \\ EIJI SUNAMI ${ }^{1}$, KOKI TAKAHASHI ${ }^{2}$, HIROKAZU NAGAWA ${ }^{1}$ and JOJI KITAYAMA ${ }^{1}$ \\ Departments of ${ }^{1}$ Surgical Oncology, and ${ }^{2}$ Transfusion Medicine, Faculty of Medical Sciences, \\ the University of Tokyo, Tokyo 113-8655, Japan
}

Received December 20, 2011; Accepted February 1, 2012

DOI: $10.3892 / \mathrm{ol} .2012 .583$

\begin{abstract}
Adiponectin is a hormone secreted by adipose tissue and has a variety of functions including the inhibition of tumor growth. The expression and function of the two major adiponectin receptors, AdipoR1 and AdipoR2, in malignant tissue have not been well characterized. In the present study, we evaluated the mRNA levels of AdipoR1 and AdipoR2 expression in 48 surgically resected colorectal cancer specimens, as well as normal colonic mucosa, by quantitative RT-PCR. The values obtained were standardized by $\beta$-actin mRNA, and the correlation between their relative expression levels and the clinicopathological characteristics of the patients was examined. The relative expression levels of AdipoR1 and AdipoR2 were significantly reduced in cancer tissue compared with normal tissue (AdipoR1: $0.97 \pm 0.39$ vs. $1.37 \pm 0.41, \mathrm{P}<0.0001$; AdipoR2: $0.92 \pm 0.31$ vs. $1.60 \pm 0.46, \mathrm{P}<0.0001)$. AdipoR1 and AdipoR2 levels were further reduced in tumors with nodal metastases and the difference was statistically significant in the case of AdipoR2 ( $0.79 \pm 0.27$ vs. $1.02 \pm 0.30, \mathrm{P}=0.012)$. The results of this study demonstrated that the expression levels of adiponectin receptors are reduced in cancer specimens compared to normal tissue, indicating a downregulation in the course of the development and progression of colorectal cancer. Since adiponectin is abundantly present in the whole body and has inhibitory effects on cancer cells, this downregulation of the receptors may be an escape mechanism of malignant cells from the suppressive effects of adiponectin.
\end{abstract}

\section{Introduction}

Obesity not only increases the risk of insulin resistance or cardiovascular diseases, but has also been identified as a risk

Correspondence to: Dr Masaya Hiyoshi, Department of Surgical Oncology, Faculty of Medical Sciences, the University of Tokyo, 7-3-1 Hongo, Bunkyo-ku, Tokyo 113-8655, Japan

E-mail: hiyosim-sur@h.u-tokyo.ac.jp

Key words: colorectal cancer, adiponectin receptor, lymph node metastasis factor for various forms of cancer, including breast, endometrial, colon and rectal, kidney, pancreatic, biliary, ovarian, cervical, liver and prostate cancer $(1,2)$. Several biological mechanisms have been proposed to explain the risk of cancer in obesity, including the secretion of steroid hormones, insulin, insulin-like growth factors and adipokines (3-5).

It is known that adipose tissue is not only a fat-storing tissue but also the largest endocrine organ in the body, producing various cytokines including adiponectin (6). Adiponectin, also known as gelatin-binding protein-28 (GPD28), AdipoQ, or ACRP30, is a peptide hormone secreted exclusively by adipocytes (7), and has been shown to have suppressive effects on tumor development (8-10). Adiponectin is usually abundant in human plasma, with concentrations ranging from 5 to $30 \mu \mathrm{g} / \mathrm{ml}$ and accounting for up to $0.05 \%$ of total plasma protein (11). Plasma concentrations of adiponectin are known to be inversely correlated with the risk of various cancers, including gastric $(12)$, breast $(13,14)$, prostate $(15,16)$, endometrial $(17,18)$ and renal cell carcinoma (19). This evidence strongly suggests a potential suppressive role of adiponectin on the development of various types of cancer, particularly in obesity-related carcinogenesis.

The adiponectin receptor exists in two isoforms; adiponectin receptor 1 (AdipoR 1 ) and adiponectin receptor 2 (AdipoR2) (20). In mice, AdipoR1 is abundantly expressed in skeletal muscle, whereas AdipoR2 is predominantly expressed in the liver (20). In humans, AdipoR1 and AdipoR2 have been reported to be expressed in adipocytes (21), skeletal muscle cells (22), vascular smooth muscle cells, macrophages (23), pancreatic $\beta$ cells $(24)$ and liver $(25,26)$. The expression of adiponectin receptors has also been reported in various cancer tissues (27-32), although the results are still controversial, and the role of the receptor expression in tumor tissues remains to be elucidated.

In a previous study by Otani et al (39), using quantitative reverse transcription polymerase chain reaction (RT-PCR) and immunohistochemical staining, it was demonstrated that the expression of AdipoR2 was significantly decreased in gastric cancer tissues compared to normal colorectal tissue. In addition, AdipoR1 levels tended to be decreased.

In the present study, we aimed to examine the expression levels of AdipoR1 and AdipoR2 in human colorectal cancer 
Table I. Expression of AdipoR1 and AdipoR2 mRNA in normal colorectal mucosa and clinical or pathological factors.

\begin{tabular}{|c|c|c|c|c|c|}
\hline Factor & (n) & AdipoR1 & P-value & AdipoR2 & P-value \\
\hline \multicolumn{6}{|l|}{ Age } \\
\hline$\geq 67$ & 23 & $1.42 \pm 0.43$ & 0.45 & $1.65 \pm 0.41$ & 0.55 \\
\hline$\leq 66$ & 25 & $1.32 \pm 0.43$ & $1.54 \pm 0.50$ & & \\
\hline \multicolumn{6}{|l|}{ Gender } \\
\hline Male & 26 & $1.30 \pm 0.41$ & 0.17 & $1.54 \pm 0.45$ & 0.24 \\
\hline Female & 22 & $1.46 \pm 0.40$ & $1.67 \pm 0.48$ & & \\
\hline \multicolumn{6}{|c|}{$\mathrm{BMI}\left(\mathrm{kg} / \mathrm{m}^{2}\right)$} \\
\hline$\geq 22$ & 23 & $1.35 \pm 0.47$ & 0.92 & $1.61 \pm 0.50$ & 0.50 \\
\hline$<22$ & 25 & $1.38 \pm 0.35$ & $1.58 \pm 0.43$ & & \\
\hline \multicolumn{6}{|l|}{ Location } \\
\hline Colon & 33 & $1.48 \pm 0.36$ & $0.0040^{\mathrm{a}}$ & $1.73 \pm 0.38$ & $0.0012^{\mathrm{a}}$ \\
\hline Rectum & 15 & $1.12 \pm 0.40$ & $1.29 \pm 0.48$ & & \\
\hline
\end{tabular}

Relative mRNA levels were examined against the internal control ( $\beta$-actin) with quantitative RT-PCR, and P-values were evaluated with the Wilcoxon rank sum tests. ${ }^{a} \mathrm{P}<0.05$. BMI, body mass index.

tissue and investigate the clinicopathological implication of their expression in colorectal cancer.

\section{Patients and methods}

Patients and samples. Colorectal cancer tissues and normal colonic mucosa were obtained from the surgical specimens of 48 patients who underwent surgery at the Department of Surgical Oncology in the University of Tokyo Hospital from November 2008 to July 2009. The diagnosis of colorectal cancer was confirmed by histological analysis. According to the location, $17(36 \%)$ cases were classified as sigmoid colon cancers, 9 (19\%) ascending colon, $15(31 \%)$ rectal, 1 (2\%) transverse colon, $4(8 \%)$ cecal, and $2(4 \%)$ cases were descending colon cancers. Cancer and normal tissue samples were obtained from surgically removed specimens in the operating room using a surgical knife. The samples were rapidly submerged in RNAlater RNA stabilization reagent (Qiagen, Hilden, Germany) and stored at $4^{\circ} \mathrm{C}$ overnight. The samples were then stored in a freezer at below $-20^{\circ} \mathrm{C}$ until analysis. This study was conducted with the approval of the Ethics Committee of the University of Tokyo.

Clinicopathological analysis. The following clinicopathological characteristics were evaluated according to the expression of AdipoR1 and AdipoR2: Gender, age, body mass index, tumor location, postoperative histological lymph node metastasis, depth of wall invasion, grade of differentiation, lymphovascular invasion status and UICC (Union for International Cancer Control) stage of the resected cancer specimens.

Quantitative RT-PCR. The sample tissues were homogenized, and the total mRNA was extracted following the manufacturer's instructions using the RNeasy mini kit (Qiagen). The concentrations of the total mRNA samples obtained were measured using a GeneQuant RNA/DNA calculator (Pharmatica GE
Healthcare Bio-Sciences, Tokyo, Japan). Reverse transcription was performed using $1 \mu \mathrm{g}$ of total mRNA, and cDNA was prepared using a High-Capacity cDNA reverse transcription kit (Applied Biosystems Japan, Tokyo), according to the manufacturer's instructions. Real-time PCR assays of AdipoR1 and AdipoR2 mRNA expression levels were performed using the 7500 Fast Real-Time PCR system (Applied Biosystems Japan) and the reagents of TaqMan Fast Universal PCR Master mix (2X) (Applied Biosystems Japan), according to the manufacturer's instructions. The primers of AdipoR1 and AdipoR2 were products of Applied Biosystems (Foster City, CA, USA), and the assay IDs in TaqMan gene expression assays were Hs00360422_ml and Hs00226105_ml, respectively. The level of adiponectin receptor gene expression was calculated from the standard curve, and quantitative normalization of cDNA in each sample was performed using the expression of the $\beta$-actin gene (primer: TaqMan Endogenous Control Human ACTB, Applied Biosystems) as an internal control.

Statistical analysis. Statistical analyses were performed with JMP8.0 (SAS Institute, Cary, NJ, USA). The correlation between the clinicopathological factors and the expression levels of adiponectin receptors was assessed using the nonparametric Wilcoxon rank sum tests or the Kruskal-Wallis test. $\mathrm{P}<0.05$ was considered to indicate a statistically significant result.

\section{Results}

Clinicopathological characteristics of the patients and the expression of AdipoR1 and AdipoR2 in normal colorectal mucosa. The clinicopathological parameters of the 48 patients included in the study and the mRNA expression of adiponectin receptors in the normal mucosa of the resected colorectal 
Table II. Expression of AdipoR1 and AdipoR2 mRNA in colorectal cancer and clinical or pathological factors.

\begin{tabular}{|c|c|c|c|c|c|}
\hline Factor & (n) & AdipoR1 & P-value & AdipoR2 & P-value \\
\hline \multicolumn{6}{|l|}{ Age } \\
\hline$\geq 67$ & 23 & $1.04 \pm 0.40$ & \multirow[t]{2}{*}{0.13} & $0.93 \pm 0.33$ & \multirow[t]{2}{*}{0.59} \\
\hline$\leq 66$ & 25 & $0.86 \pm 0.38$ & & $0.88 \pm 0.28$ & \\
\hline \multicolumn{6}{|l|}{ Gender } \\
\hline Male & 26 & $1.01 \pm 0.42$ & \multirow[t]{2}{*}{0.57} & $0.95 \pm 0.34$ & \multirow[t]{2}{*}{0.36} \\
\hline Female & 22 & $0.91 \pm 0.36$ & & $0.88 \pm 0.27$ & \\
\hline \multicolumn{6}{|l|}{ Location } \\
\hline Colon & 33 & $0.94 \pm 0.43$ & \multirow[t]{2}{*}{0.58} & $0.90 \pm 0.33$ & \multirow[t]{2}{*}{0.54} \\
\hline Rectum & 15 & $1.01 \pm 0.32$ & & $0.96 \pm 0.26$ & \\
\hline \multicolumn{6}{|l|}{ Depth } \\
\hline$<\mathrm{MP}$ & 10 & $1.03 \pm 0.30$ & \multirow[t]{2}{*}{0.70} & $0.91 \pm 0.16$ & \multirow[t]{2}{*}{0.87} \\
\hline$>\mathrm{SS}$ & 38 & $0.97 \pm 0.43$ & & $0.94 \pm 0.34$ & \\
\hline \multicolumn{6}{|l|}{ Histology } \\
\hline Differentiated & 45 & $0.97 \pm 0.39$ & \multirow[t]{2}{*}{0.55} & $0.92 \pm 0.30$ & \multirow[t]{2}{*}{0.41} \\
\hline Undifferentiated & 3 & $0.82 \pm 0.46$ & & $0.77 \pm 0.48$ & \\
\hline \multicolumn{6}{|l|}{ Lymphatic invasion } \\
\hline Negative & 29 & $0.98 \pm 0.34$ & \multirow[t]{2}{*}{0.86} & $0.97 \pm 0.31$ & \multirow[t]{2}{*}{0.15} \\
\hline Positive & 19 & $0.95 \pm 0.47$ & & $0.84 \pm 0.30$ & \\
\hline \multicolumn{6}{|l|}{ Venous invasion } \\
\hline Negative & 7 & $0.90 \pm 0.27$ & \multirow[t]{2}{*}{0.62} & $0.84 \pm 0.26$ & \multirow[t]{2}{*}{0.45} \\
\hline Positive & 41 & $0.98 \pm 0.41$ & & $0.93 \pm 0.32$ & \\
\hline \multicolumn{6}{|c|}{ Lymph node metastasis } \\
\hline Negative & 26 & $1.05 \pm 0.38$ & \multirow[t]{2}{*}{0.15} & $1.02 \pm 0.30$ & \multirow[t]{2}{*}{$0.012^{\mathrm{a}}$} \\
\hline Positive & 22 & $0.86 \pm 0.39$ & & $0.79 \pm 0.27$ & \\
\hline \multicolumn{6}{|l|}{ Distant metastasis } \\
\hline Negative & 43 & $0.97 \pm 0.36$ & \multirow[t]{2}{*}{0.68} & $0.93 \pm 0.31$ & \multirow[t]{2}{*}{0.21} \\
\hline Positive & 5 & $0.89 \pm 0.69$ & & $0.75 \pm 0.22$ & \\
\hline
\end{tabular}

Relative mRNA levels were examined against the internal control ( $\beta$-actin) with quantitative RT-PCR, and P-values were evaluated with the Wilcoxon rank sum tests. ${ }^{\mathrm{a}} \mathrm{P}<0.05$. MP, muscularis propria; $\mathrm{SS}$, subserosa.

cancer specimens are shown in Table I. The samples expressed significant mRNA levels of AdipoR1 and AdipoR2. AdipoR2 was expressed at relatively higher levels than AdipoR1, but the expression levels of AdipoR1 and AdipoR2 did not show a significant correlation with age, gender or body mass index (BMI). Notably, however, the expression levels of both AdipoR1 and AdipoR2 were significantly higher in colonic compared to rectal mucosa (AdipoR1: $1.48 \pm 0.36$ vs. $1.12 \pm 0.40, \mathrm{P}=0.0040$; AdipoR2: $1.73 \pm 0.38$ vs. $1.29 \pm 0.48, \mathrm{P}=0.0012)$.

Expression of AdipoR1 and AdipoR2 in colorectal cancer tissue. The standardized expression levels of the adiponectin receptors in colorectal cancer specimens were compared with the expression levels in normal mucosa. As a result, both AdipoR1 and AdipoR2 were markedly downregulated in cancer tissue (AdipoR1: cancer tissue 0.97 \pm 0.39 , normal mucosa $1.37 \pm 0.41, \mathrm{P}<0.0001$; AdipoR2: cancer tissue 0.92 \pm 0.31 , normal mucosa $1.60 \pm 0.46, \mathrm{P}<0.0001$ ) (Fig. 1). To evaluate the clinicopathological implications of the downregulation of adiponectin receptors in colorectal cancer, its correlation with the clinicopathological parameters of the patients was analyzed. Neither AdipoR1 nor AdipoR2 expression correlated with either age, gender, tumor location, depth of invasion, histology, venous or lymphatic invasion (Table II). However, there was a tendency of lower expression of the two receptors in tumors with lymph node metastasis than in tumors without nodal metastasis, and in the case of AdipoR2, the difference was statistically significant (AdipoR1: $0.88 \pm 0.40$ vs. $1.05 \pm 0.41$, $\mathrm{P}=0.15$; AdipoR2: $0.79 \pm 0.27$ vs. $1.02 \pm 0.30, \mathrm{P}=0.012$ ).

\section{Discussion}

Numerous studies have suggested that adiponectin has suppressive effects on cancer development and progression 
Adipo R1

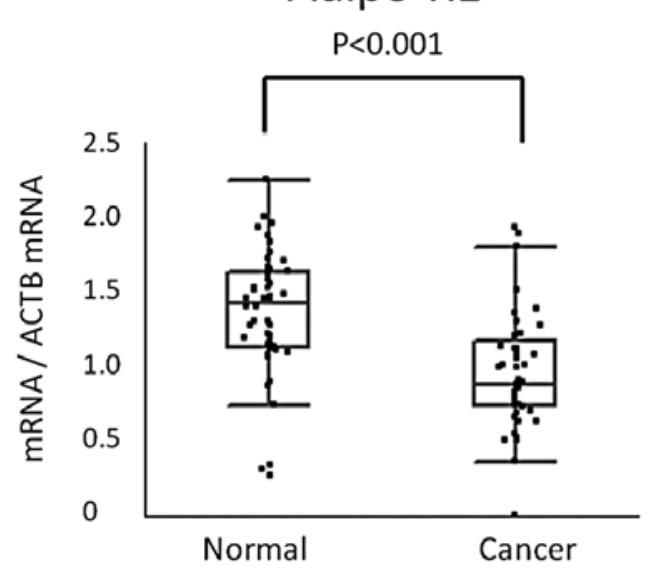

Adipo R2

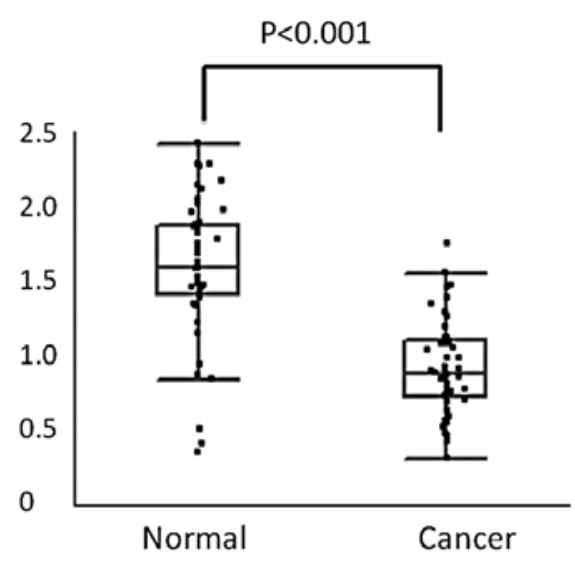

Figure 1. mRNA expression levels of AdipoR1 and AdipoR2 in cancer specimens and normal mucosa were evaluated using real-time RT-PCR. Values are normalized to the level of $\beta$-actin. The expression levels of AdipoRs were significantly lower in the cancer specimens compared to the normal mucosa.

(33). The direct inhibitory effect of adiponectin on the growth of colorectal cancer cells $(34,35)$, suggestive of the expression of functional adiponectin receptors in colorectal cancer cells, has been demonstrated, and previous studies using human specimens have provided evidence that AdipoR1 and AdipoR2 are expressed in colorectal cancer tissue at mRNA and protein levels $(31,36,37)$.

In the present study, we also confirmed the expression of AdipoR1 and AdipoR2 in colorectal cancer tissues at the mRNA level. These receptors were also expressed in the normal colonic mucosa at the mRNA level. However, compared to normal epithelium, their expression levels were significantly decreased in cancer specimens. This result is consistent with the results found in prostate (38) and gastric cancer (39). However, the expression level of adiponectin receptors in human colorectal cancer tissue remains controversial. Using immunohistochemistry, Williams et al (31) reported that both AdipoR1 and AdipoR2 are expressed in most colorectal carcinomas but not in normal colorectal tissue. Conversely, although not comparing normal and cancerous tissues from the same patients, Yoneda et al (36) reported that the two isoforms of adiponectin receptors were expressed in colorectal cancer cells at the same levels as in normal colonic epithelium. In the present study, therefore, the expression levels of AdipoR1 and AdipoR2 in human colorectal cancer specimens were compared with those in their normal counterparts, and both were significantly decreased in cancer tissues. Additionally, results of an analysis of the correlation of adiponectin receptor expression with clinicopathological parameters of the patients revealed that AdipoR2 mRNA expression was lower in tumors with lymph node metastasis than in those without.

Using immunohistochemistry, Byeon et al reported that AdipoR1 and AdipoR2 expression levels inversely correlated with the T stage (37). These authors also found that AdipoR2 expression inversely correlated with the AJCC (American Joint Committee on Cancer) stage and the status of lymphovascular invasion. Their findings together with those of this study led to the hypothesis that receptor downregulation in colorectal cancer would be beneficial for the growth of cancer cells in metastatic sites, particularly lymph nodes, and could facilitate the development of nodal metastasis.

Another notable finding in the present study was the significantly lower expression of AdipoR1 and AdipoR2 in the normal mucosa of the rectum than in that of the colon. The mRNA levels of AdipoR1 and AdipoR2 in mucosal tissues of the stomach or small intestine evaluated by the same method were similar to those of the rectum (40). Therefore, compared to the rest of the gastrointestinal tract, colonic mucosa apparently expresses higher levels of adiponectin receptor. Since colonic epithelia have specific functions as well as different kinetics compared to those of the rest of the gastrointestinal tract $(41,42)$, our data suggest the possibility of a relevant physiological function of adiponectin receptors in the colonic mucosa, and further studies are required to elucidate this hypothesis.

The finding in our study of the decreased expression of adiponectin receptors in colorectal cancer compared to their normal counterparts is not in concordance with previous studies (36). This discrepancy may be attributed to the different samples investigated and the different methodologies applied. Since adiponectin is known to inhibit the growth of colorectal cancer cells, our data support the hypothesis that the downregulation of AdipoR1 and AdipoR2 expression in colorectal epithelium may have a protective role in colorectal carcinogenesis.

In conclusion, we have demonstrated that the two major receptors for adiponectin, AdipoR1 and AdipoR2, were downregulated in colorectal cancer, and particularly decreased in tumors with lymph node metastasis. To the best of our knowledge, this is the first study to demonstrate the inverse correlation between adiponectin receptor expression and colorectal carcinogenesis and nodal metastasis. Since adiponectin is abundantly present in the human circulation, the downregulation of its receptor may be an escape mechanism of malignant cells against the suppressive effect of adiponectin in the course of cancer development and metastasis. 


\section{References}

1. Wolk A, Gridley G, Svensson M, et al: A prospective study of obesity and cancer risk (Sweden). Cancer Causes Control 12: $13-21,2001$.

2. Calle EE, Rodriguez $\mathrm{C}$, Walker-Thurmond $\mathrm{K}$ and Thun MJ: Overweight, obesity, and mortality from cancer in a prospectively studied cohort of U.S. adults. N Engl J Med 348: 1625-1638, 2003

3. Key TJ, Allen NE, Verkasalo PK and Banks E: Energy balance and cancer: the role of sex hormones. Proc Nutr Soc 60: 81-89, 2001.

4. Housa D, Housova J, Vernerova Z and Haluzik M: Adipocytokines and cancer. Physiol Res 55: 233-244, 2006.

5. Fottner C, Hoeflich A, Wolf E and Weber MM: Role of the insulin-like growth factor system in adrenocortical growth control and carcinogenesis. Horm Metab Res 36: 397-405, 2004.

6. Barb D, Williams C, Neuwirth A and Mantzoros C: Adiponectin in relation to malignancies: a review of existing basic research and clinical evidence. Am J Clin Nutr 86: s858-866, 2007.

7. Maeda K, Okubo K, Shimomura I, Funahashi T, Matsuzawa Y and Matsubara K: cDNA cloning and expression of a novel adipose specific collagen-like factor, apM1 (AdiPose Most abundant Gene transcript 1). Biochem Biophys Res Commun 221: 286-289, 1996.

8. Bub JD, Miyazaki T and Iwamoto Y: Adiponectin as a growth inhibitor in prostate cancer cells. Biochem Biophys Res Commun 340: 1158-1166, 2006

9. Ishikawa M, Kitayama J, Yamauchi T, et al: Adiponectin inhibits the growth and peritoneal metastasis of gastric cancer through its specific membrane receptors AdipoR1 and AdipoR2. Cancer Sci 98: 1120-1127, 2007.

10. Dieudonne MN, Bussiere M, Dos Santos E, Leneveu MC, Giudicelli Y and Pecquery R: Adiponectin mediates antiproliferative and apoptotic responses in human MCF7 breast cancer cells. Biochem Biophys Res Commun 345: 271-279, 2006.

11. Chandran M, Phillips S, Ciaraldi T and Henry R: Adiponectin: more than just another fat cell hormone? Diabetes Care 26 2442-2450, 2003.

12. Ishikawa M, Kitayama J, Kazama S, Hiramatsu T, Hatano K and Nagawa H: Plasma adiponectin and gastric cancer. Clin Cancer Res 11: 466-472, 2005.

13. Miyoshi Y, Funahashi T, Kihara S, et al: Association of serum adiponectin levels with breast cancer risk. Clin Cancer Res 9: 5699-5704, 2003.

14. Mantzoros C, Petridou E, Dessypris N, et al: Adiponectin and breast cancer risk. J Clin Endocrinol Metab 89: 1102-1107, 2004.

15. Goktas S, Yilmaz M, Caglar K, Sonmez A, Kilic S and Bedir S: Prostate cancer and adiponectin. Urology 65: 1168-1172, 2005.

16. Michalakis K, Williams C, Mitsiades N, et al: Serum adiponectin concentrations and tissue expression of adiponectin receptors are reduced in patients with prostate cancer: a case control study. Cancer Epidemiol Biomarkers Prev 16: 308-313, 2007.

17. Dal Maso L, Augustin L, Karalis A, et al: Circulating adiponectin and endometrial cancer risk. J Clin Endocrinol Metab 89: 1160-1163, 2004

18. Petridou E, Mantzoros C, Dessypris N, et al: Plasma adiponectin concentrations in relation to endometrial cancer: a case-contro study in Greece. J Clin Endocrinol Metab 88: 993-997, 2003.

19. Spyridopoulos T, Petridou E, Skalkidou A, et al: Low adiponectin levels are associated with renal cell carcinoma: a case-control study. Int J Cancer 120: 1573-1578, 2007.

20. Yamauchi T, Kamon J, Ito Y, et al: Cloning of adiponectin receptors that mediate antidiabetic metabolic effects. Nature 423: 762-769, 2003.

21. Berner HS, Lyngstadaas SP, Spahr A, et al: Adiponectin and its receptors are expressed in bone-forming cells. Bone 35: 842-849, 2004.

22. Staiger H, Kaltenbach S, Staiger K, et al: Expression of adiponectin receptor mRNA in human skeletal muscle cells is related to in vivo parameters of glucose and lipid metabolism. Diabetes 53: 2195-2201, 2004
23. Chinetti G, Zawadski C, Fruchart JC and Staels B: Expression of adiponectin receptors in human macrophages and regulation by agonists of the nuclear receptors PPARalpha, PPARgamma, and LXR. Biochem Biophys Res Commun 314: 151-158, 2004.

24. Kaltenbach S, Staiger H, Weisser M, et al: Adiponectin receptor gene expression in human skeletal muscle cells is not regulated by fibrates and thiazolidinediones. Int J Obes (Lond) 29: 760-765, 2005.

25. Jonsson JR, Moschen AR, Hickman IJ, et al: Adiponectin and its receptors in patients with chronic hepatitis C. J Hepatol 43 929-936, 2005.

26. Shimizu A, Takamura T, Matsuzawa N, et al: Regulation of adiponectin receptor expression in human liver and a hepatocyte cell line. Metabolism 56: 1478-1485, 2007.

27. Barresi V, Grosso M, Giuffre G, Tuccari G and Barresi G: The expression of adiponectin receptors Adipo-R1 and Adipo-R2 is associated with an intestinal histotype and longer survival in gastric carcinoma. J Clin Pathol 62: 705-709, 2009.

28. Petridou E, Mitsiades N, Gialamas S, et al: Circulating adiponectin levels and expression of adiponectin receptors in relation to lung cancer: two case-control studies. Oncology 73: 261-269, 2007.

29. Takahata C, Miyoshi Y, Irahara N, Taguchi T, Tamaki Y and Noguchi S: Demonstration of adiponectin receptors 1 and 2 mRNA expression in human breast cancer cells. Cancer Lett 250: 229-236, 2007.

30. Dalamaga M, Migdalis I, Fargnoli J, et al: Pancreatic cancer expresses adiponectin receptors and is associated with hypoleptinemia and hyperadiponectinemia: a case-control study. Cancer Causes Control 20: 625-633, 2009.

31. Williams CJ, Mitsiades N, Sozopoulos E, et al: Adiponectin receptor expression is elevated in colorectal carcinomas but not in gastrointestinal stromal tumors. Endocr Relat Cancer 15: 289-299, 2008

32. Chou SH, Tseleni-Balafouta S, Moon HS, et al: Adiponectin receptor expression in human malignant tissues. Horm Cancer 1: $136-145,2010$

33. Kelesidis I, Kelesidis T and Mantzoros CS: Adiponectin and cancer: a systematic review. Br J Cancer 94: 1221-1225, 2006.

34. Fujisawa T, Endo H, Tomimoto A, et al: Adiponectin suppresses colorectal carcinogenesis under the high-fat diet condition. Gut 57: 1531-1538, 2008.

35. Sugiyama M, Takahashi $\mathrm{H}$, Hosono $\mathrm{K}$, et al: Adiponectin inhibits colorectal cancer cell growth through the AMPK/mTOR pathway. Int J Oncol 34: 339-344, 2009.

36. Yoneda K, Tomimoto A, Endo H, et al: Expression of adiponectin receptors, AdipoR1 and AdipoR2, in normal colon epithelium and colon cancer tissue. Oncol Rep 20: 479-483, 2008

37. Byeon JS, Jeong JY, Kim MJ, et al: Adiponectin and adiponectin receptor in relation to colorectal cancer progression. Int J Cancer, 2010.

38. Michalakis K, Williams CJ, Mitsiades N, et al: Serum adiponectin concentrations and tissue expression of adiponectin receptors are reduced in patients with prostate cancer: a case control study. Cancer Epidemiol Biomarkers Prev 16: 308-313, 2007.

39. Otani K, Kitayama J, Kamei T, et al: Adiponectin receptors are downregulated in human gastric cancer. J Gastroenterol 45: 918-927, 2010.

40. Otani K, Kitayama J, Yasuda K, et al: Adiponectin suppresses tumorigenesis in Apc(Min)(/+) mice. Cancer Lett 288: 177-182, 2010.

41. Cummings JH: Absorption and secretion by the colon. Gut 16 323-329, 1975.

42. Cheng H, Bjerknes M and Amar J: Methods for the determination of epithelial cell kinetic parameters of human colonic epithelium isolated from surgical and biopsy specimens. Gastroenterology 86: 78-85, 1984. 